\title{
Structured Abstract
}

Purpose - The purpose of this study is to assess the effectiveness of field sponsorship through sponsor recall and recognition across two environments that differ on the degree of felt presence they trigger among viewers: on-site and television. A series of research hypotheses concerning the interaction effects of viewing environment, event-sponsor congruence, and arousal intensity were developed.

Design/methodology/approach - In order to test the effect of the viewing environment, a field experiment was conducted where 44 ice hockey fans attended a professional ice hockey game in the local team's arena whereas 44 others saw the same game, at the same time, on television. The participants were randomly assigned to one of the two game viewing conditions.

Findings - A higher level of arousal was detrimental to sponsor identification in a manner consistent with the intensity of processing principle according to which arousal polarizes attention resources on the arousing stimulus (the event) while diverting resources away from the peripheral stimuli (the sponsors). In addition, because event congruent sponsors are more superficially processed in comparison with incongruent ones, this negative impact was more pronounced for the former group. This was qualified by a three-way interaction with the type of environment; the on-site, direct, audience was less affected by the processing intensity principle and exhibited better recall and recognition than the television audience as arousal and congruency increased whereas, at lower level of arousal, higher event-sponsor congruence hampered on-site sponsor identification in comparison with television.

Research limitations/implications - The findings were obtained in the context of a single sports event; additional studies need to be conducted using different sports. In addition, the comparison of on-site audience with other types of media audiences (e.g., on-line broadcasting) is warranted.

Practical implications - Arousal intensity results from the game's drama which is a function of game importance and game outcome uncertainty. Hence, except for low stakes games (e.g., preseason matches, exhibitions), initiatives that promote a leveled playing field such as salary cap, financial fair play, and open leagues are likely to jeopardize sponsor identification, particularly for congruent sponsors. With respect to the impact of the viewing environment, congruent sponsors should reap superior benefits from the television audience when stakes are low. However, when stakes are high, their benefits will accrue to a greater extent from on-site spectators.

Originality/value - This is the first study to offer a rigorous comparison of sponsorship's impact on direct (on-site) versus indirect (television) audiences through a field experiment. This is also the first research to provide a framework based on the processing intensity principle that encompasses predictions related to arousal and its interaction with event-sponsor congruence and the viewing environment. Within this perspective, the degree of sponsor integration in the viewing environment is instrumental in predicting sponsorship outcomes.

Keywords: Sponsorship, recall, recognition, identification, television, arena, processing intensity, sports marketing

Article Classification: Research paper 
Professional sports events such as golf tournaments, football games, and the like offer great opportunities for companies to promote their brands and products through sponsorship (Ngan et al., 2011). During these events it is quite common to see a significant number of sponsors whose main marketing communication strategy consists in being visually present by means of their brand's logo and/or slogan. This type of sponsorship deployment, called field sponsorship, corresponds to "messages that are limited to a brand name or to a few words summarizing the brand's positioning platform" (Pham and Vanhuele, 1997, p. 407). Typically, these messages are found on signage very close to the field of play, or on the players' outfits, and do not interfere with the event itself, or its television or on-line broadcast (Lardinoit and Quester, 2001).

Because they attract large audiences, professional sports events are generally broadcasted on television and on the internet. Field sponsors therefore benefit from having their message communicated to both on-site and media audiences. Although studies have examined the effectiveness of field sponsorship activities in the context of on-site surveys (e.g., Bennett, 1999; Nicholls et al., 1999; Quester, 1997; Tripodi et al., 2003) and surveys of television audiences (e.g., d'Ydewalle et al., 1988; Lardinoit and Quester, 2001; Pope and Vosge, 1997), there has not been any research formally comparing the effectiveness of field sponsorship in these two viewing environments. Such research is however very relevant for sponsors who would like to know how much return on their investment can be expected from each type of audience. It is also relevant for marketing researchers who seek to understand the environmental conditions that impact the effectiveness of sponsorship activities in general, and that of field sponsorship in particular.

Sporting events are sought after venues for sponsors, in part due to the intense state of arousal they generate among spectators (Bal et al., 2010; Newell et al., 2001). However, the type 
of viewing environment in which spectators are exposed during these sporting events may modify the role that arousal plays in the processing of sponsor-related information. Arousal intensity during on-site attendance may impact sponsorship effectiveness differently than during a television broadcast of the event due to completely different sensorial surroundings (e.g., proximity between spectators and action, intensity of stimuli, direct witnessing of the event) resulting in viewers having significantly different feelings of presence - i.e., "being there" or not (Nicovich, 2005). In addition, the intensity of presence felt by on-site viewers compared with those watching from home could impact the processing of sponsorship stimuli as a function of their level of congruence with the event. Specifically, in a high presence viewing environment, sponsors showing some incongruence with the event may benefit from a greater level of processing elaboration since their unexpected nature make them stand out during an ongoing sporting event cluttered with competing messages (Fleck and Quester, 2007; Mandler, 1982). Consequently, this research focuses on the impact of arousal and event-sponsor congruence on consumer responses to sponsorship stimuli and how it is likely to be moderated by the presence felt in the viewing environment.

In order to investigate these issues in the domain of sport sponsorship effectiveness, a field experiment aimed at comparing the impact of field sponsorship on consumer responses in two viewing environments was conducted in the context of a professional ice hockey game. Using measures of recall and recognition of sponsors obtained among sports fans who followed the game, at the same time, either on-site or on television as well as measures of arousal during the game, this study aims at clarifying the interplay between feelings of presence (through the viewing environment), arousal, and event-sponsor congruence in understanding sponsorships' impact on consumer memory. 


\section{Background}

Researchers interested in sponsorship issues have recently started to examine the generalizability of their models across different contexts. For instance, Olson (2010) has investigated whether a given sponsorship model can hold in both a sports and cultural sponsorship contexts. However, research regarding the comparison of sponsorship effectiveness across different viewing environments, such as live attendance versus television broadcast, is scarce. In general, sponsorship studies focus either on audiences attending on-site or on audiences watching on television without comparing both. These studies are very heterogeneous regarding the populations examined, the time and place of data collection, as well as the types of events investigated. Furthermore, they rely on very different research designs and methods. Therefore, comparing them directly to estimate the relative effectiveness of on-site versus mediated sponsorship is a perilous exercise.

For instance, the results of Lardinoit and Derbaix's (2001) investigation of the effectiveness of sponsorship during a basket-ball game broadcast in Belgium can hardly be compared with those of Tripodi et al. (2003) concerning the sponsorship of an Australian bank during the Sydney Olympics. Similarly, the $4.83 \%$ of sponsor recall and $10 \%$ of sponsor recognition reported by Pope and Vosge (1997) among television viewers in the context of a rugby league game in Australia are difficult to pit against Quester's (1997) results of recall and recognition percentages of 22 and 68, respectively, among attendees of the Adelaide Formula 1 Grand Prix, or against Nicholls et al.'s (1999) results that indicate a 9.25\% recall in the context of a golf and a tennis tournaments in the USA.

Even when the research settings are relatively similar, the results are still difficult to compare. For instance, Bennett (1999) and d'Ydewalle et al. (1988) both studied soccer game 
fans, with the former investigating fans who watched a game on television and the latter those who were present in the stadium. The recall scores reported in the two studies are on average relatively close (i.e., about $8 \%$ ). Notwithstanding their converging results, any conclusion one would draw from comparing the results of these two studies would be tentative at best since the recall data are based on different games and sponsors.

Dekhil's (2010) research appears to be the only one with the explicit intent to contrast onsite versus television audiences within the same study. However, this research does not offer a stringent test of the merits of each environment, due to the fact that the field experiment was conducted over the entire 3-week duration of the 2004 African Cup of Nations which involved multiple games rather than a single punctual event, making the influence of extraneous factors very likely. First, on-site game attendees who participated in the study could have watched many games on television as well, which renders the actual empirical comparison akin to on-site and television versus television alone. Second, respondents were assigned to either group when they had attended, or watched, one of the 32 games of the competition having taken place in different stadiums across Tunisia. Therefore, the comparison between television and on-site was based on a different set of sponsors that might have been displayed differently as a function of the stadium in which the game took place.

The above discussion highlights the need to perform a study specifically designed to compare the effectiveness of on-site versus mediated sponsorship as regards the recall and recognition of sponsors. To overcome the difficulties in comparing in the context of a field experiment two environments that differ on a host of aspects, in this research the time and location of the event as well as the sponsors were kept constant, making the type of viewing environment the only contrasting variable. The research hypotheses put forward are anchored in 
an associative memory conceptual framework which allows integrating the role of arousal, congruence, and presence.

\section{Associative memory network}

In the context of this research, it is useful to conceive of a sports event and its sponsors as nodes in an associative memory network (e.g., Carrillat and d'Astous, 2012; Cornwell et al., 2006; Keller, 1993). When an event and a sponsor are activated together (e.g., seeing the logo of a sponsor when watching an ice hockey game), the cognitive pathway that unites these nodes is reinforced and this results in a stronger memory trace. As the memory trace strengthens, the level of activation necessary for a given node (e.g., the event) to spread to associated nodes (e.g., sponsors) decreases, hence enhancing the likelihood that consumers will recall the sponsor when prompted with the event (Collins and Loftus, 1975; Wyer and Carlston, 1979).

\section{Event-sponsor congruence}

Event-sponsor congruence may be conceptualized using the dimensions of relevancy (i.e., the extent to which the stimulus promotes understanding of the intended message) and expectancy (i.e., the extent to which the association is not surprising to the audience) (Fleck and Quester, 2007). Another approach is to split up the construct in several dimensions, such as the correspondence between the sponsor's products and the products used by participants to the event, the images of the sponsor and the event, or the geographical origins of the sponsor and the event (Carrillat et al., 2013; Olson and Thjømøe, 2011; Prendergast et al., 2010). Yet, another way of looking at event-sponsor congruence is to consider the extent to which event and sponsors fit together at an overall level of analysis; in other words to examine whether event and sponsors are perceived as well matched (Carrillat et al., 2010; Mazodier and Merunka, 2012; Speed and Thompson, 2000). This latter approach is adopted in this study, since considering 
overall congruence rather than its specific dimensions allows accounting for the many bases of congruence that different sponsors of the same event might have (Speed and Thompson, 2000) as well as for the idiosyncratic views of congruence that audience members may hold (Olson and Thjømøe, 2011).

Although there is a consensus among researchers that event-sponsor congruence has a significant influence on the processing of sponsorship stimuli, there are theoretical and empirical divergences as to whether it facilitates or hinders sponsor identification. Some studies have found that congruent event-sponsor pairs lead to a better identification of the sponsor (e.g., Cornwell et al., 2006; Simmons and Becker-Olsen, 2006; Speed and Thompson, 2000). These studies are grounded on a network perspective of consumer memory (Cornwell et al., 2005) according to which information spreads more easily between congruent nodes, which strengthens the pathway between them (Collins and Loftus, 1975; Wyer and Carlston, 1979). Other studies however have reported higher identification of incongruent sponsors (e.g., Olson and Thjømøe, 2009). The incongruence advantage is founded on a processing intensity perspective (Cornwell et al., 2005) according to which stimuli that disconfirm expectations generate more cognitive elaboration (Jagre et al., 2001) which, ultimately, strengthens associative pathways. Although the empirical evidence is stronger in favor of the positive influence of congruence over incongruence in the sponsorship domain, the theoretical underpinnings are solid for each view with both receiving ample support from psychological research (e.g., Mandler, 1982; Stangor and Macmillan, 1992). Hence, it seems that both perspectives have merit and that congruence's role in sponsorship stimuli processing is more accurately conceptualized as a moderator of the arousal-identification relationship. 


\section{Arousal}

Arousal manifests itself through excitation, alertness, and "a state of wakefulness" (Greenwald and Leavitt, 1984, p. 583). The capacity of sports events to trigger a high state of arousal (e.g., Bal et al., 2010; Pham, 1992) stems from their dramatic nature where, in contrast to scripted events, uncertainty regarding the outcome is prevalent and viewers witness the real life of participants unfolding (Bee and Madrigal, 2012; Cathelas, 1999; Cummins et al. 2012; Mason, 1999; Reid, 1970). Importantly, arousal has been shown to influence individuals' information processing according to two different principles (Cornwell et al., 2005; Kroeber-Riel, 1979; Newell et al., 2001; Pavelchak et al., 1988). The processing efficiency principle proposes that a higher level of arousal increases the processing of any information associated with the focal stimulus, which should strengthen the event-sponsor memory trace (Kroeber-Riel, 1979). In contrast, according to the processing intensity principle, an elevated arousal state enhances only the processing of the stimulus responsible for the arousal whereas it inhibits the processing of peripheral stimuli.

On the one hand, Kroeber-Riel's (1979) results show that advertisements that create stronger arousal reactions facilitate the memorization of the message elements due to more efficient processing. On the other hand, in studies focusing on advertising during the broadcast of sports events, the intensity principle view is prevalent since advertised brands are peripheral to the event. As a result, arousal impedes the recall of advertisements presented during such events. Pavelchak et al. (1988) found a negative impact of arousal on advertising recall using the Superbowl as the event context. Similarly, Newell et al. (2001) found that the recall of advertisements during the Superbowl was higher for ads appearing in the first half of the game 
than for those in the second half when television viewers' arousal level was presumably higher due to the uncertainty of the game's outcome until the very last minute.

Likewise, during a sports event, sponsors are incidental to the main story line and may not be associated at all with the arousing stimulus (i.e., the event) in consumers' minds. Therefore, in this particular context the processing intensity principle should play a greater role than the processing efficiency principle. The detrimental effect of arousal on sponsor identification that has been empirically observed during sports events is indeed consistent with the dominance of the processing intensity principle in this context. For instance, Pham (1992), as well as Walliser (1996), found a negative relationship between arousal and memory for sponsorship stimuli embedded in a soccer telecast.

According to the above explanations, incongruent sponsors are processed with more intensity than their congruent counterparts which strengthens their memory trace potential, while high arousal states impede the processing of peripheral stimuli such as sponsors. Because the associative pathway between the event and sponsor nodes needs to reach a high enough level of activation in order for identification to be possible (Collins and Loftus, 1975), the likelihood that a sponsor reaches this activation level diminishes as event sponsor congruence increases and arousal becomes elevated. At lower levels of arousal however, the negative effect of congruence on the processing of sponsors is unlikely to bring down the activation level of the event-sponsor pathway below the identification threshold. Thus:

H1a: In the context of a sports event with field sponsorship, arousal has a negative effect on sponsor recall and sponsor recognition. 
H1b: In the context of a sports event with field sponsorship, the negative effect of arousal on sponsor recall and sponsor recognition strengthens as event-sponsor congruence increases.

\section{The role of 'presence' in determining information processing mode}

As explained above, the intensity principle is likely to dominate over the efficiency principle regarding the processing of sports event sponsors; hence the latter are likely to be treated as peripheral stimuli. However, the relative power of the intensity principle compared to that of the efficiency principle should be greater in a mediated environment than in a real environment due to differences in "felt presence". Presence - or the sensation of 'being there' in some environment (IJsselsteijn et al., 2000; Heeter, 2003; Lombard and Ditton, 1997) - is a key notion in mediated communication research; especially in studies that have investigated the extent to which observers feel immersed in their viewing experience. Presence is the perception of being in an environment that comes about based on the various inputs conveyed by any of the five senses (i.e., Nicovich, 2005). When on-site, potent feelings of presence among viewers shape the perception of sponsors into a more holistic experience where they become intertwined with the event itself (e.g., Grigorovici, 2003). As a result, the sponsorship stimuli and the event are likely to be perceived as a whole which should be more conducive to the efficiency principle of processing than what happens in a mediated environment. This is consistent with the fact that all the studies having reported a negative impact of arousal on sponsor identification were conducted in a mediated environment (see Newell et al., 2001; Pavelchak et al., 1988; Pham, 1992; Walliser, 1996). According to Sheridan (1992), the weaker felt presence in a television mediated viewing experience compared to an on-site experience is explained by three main factors. Felt presence strengthens when: 1) the content of the information stimulus is a genuine 
representation of the real stimulus, 2) the viewer can freely decide which of the elements of the stimulus information to be attentive to, and 3) the viewer has an impact on the configuration of the environment.

The first factor refers to the correspondence between the viewing experience and the real environment (Nicovich, 2005). Despite technological improvements as regards picture and sound quality (frames per second, color schemes, Dolby surround, etc.), the perceptual quality (Usoh et al., 2000) of a sport event broadcasted on television is still a far cry from what one experiences in a stadium. Visual and auditory stimuli cannot be genuinely represented to viewers whereas haptic, olfactory, or taste sensations are simply not mediated by available television technologies. Studies have shown that television provides one of the weakest feeling of presence to viewers in comparison with other types of mediated environments such as 3D HDTV, video games, or augmented reality (Grigorovici, 2003; Sheridan, 1992). Hence, the felt presence triggered by the content of the stimulus information via television will be much lower than when being on-site.

Second, although game broadcasting has evolved considerably and efforts have been made to give an extended coverage of the game experience (camera shots in the lockers or on the bench, interviews with coaches and players, etc.), in essence television dictates what perspective of the game viewers have access to and, at the same time, what sponsorship stimuli they are exposed to (Cummins et al., 2012; Nebenzahl and Hornik, 1985). In a stadium or in an arena, spectators decide for themselves what to watch at any point in time. They can follow the puck, or the ball, or instead just focus on their favorite player throughout the game regardless of where the action takes place. In addition, they can switch among these different foci at will (Turley and Shannon, 2000). Ample empirical evidence demonstrates that the extent to which one has the 
possibility to choose her or his own viewpoint fosters feelings of presence. For instance, the size of the viewing angle, as well as the proportion of the visual field occupied by the focal stimuli (Lombard and Ditton, 1997) is likely to strengthen the feeling of presence. Hatada et al. (1980) found that as the viewing angle increased from 20 to 100 degrees (horizontally and vertically) so did the sensation of reality experienced. In addition, Prothero and Hoffman (1995) and Prothero et al. (1995) found that perceptions of "being there" are significantly stronger when the viewing angle increases from 60 to 105 degrees. Furthermore, the depth of the visual experience (i.e., the impression of perspective) is another strong determinant of felt presence (e.g., Edwards and Gangadharbatla, 2001; Li et al., 2002). For instance, IJsselsteijn et al. (1998) reported a correlation of .54 between image depth and felt presence. Hence, an on-site (3-dimensional) context leads to striking differences in terms of felt presence in comparison with a television mediated (2-dimensional) viewing environment.

Third, while viewers' impact on the configuration of the real environment (or perception of such influence) is null when mediated by television; when on-site, viewers are part of the environment itself and hence can shape its configuration. Ko et al. (2011) have shown that dimensions such as "augmented service quality" or "interaction quality" are key components of the experience of attendees at sports events. Importantly, both dimensions imply that viewers' behaviors are an essential part of the event experience. The augmented service quality dimension refers to the different in-game promotions or competitions that are organized for sports events attendees. Through these activities, attendees' performance becomes part of the event and shapes the configuration of the environment (in addition, these activities often occur during the broadcast's commercial breaks and are not visible by television viewers). In the same vein, the second dimension - interaction quality - refers to the interaction with other fans in the arena or 
the stadium, as fans engage in supporting songs or rituals that only take place in a muted format when watching on television, if at all. Based on the above assessment, all three factors will lead to superior feelings of presence when on-site as opposed to being in a television mediated environment, which should strengthen the influence of the efficiency principle of processing at the expense of the intensity principle of processing.

Empirical evidence shows that when feelings of presence are stronger viewers are less likely to disentangle commercial messages from their environment since they adopt a holistic processing mode (e.g., Nicovich 2005). For instance, Grigorovici (2003) reports that viewers in a high felt presence environment are less aware of embedded product placements although they exhibit higher brand recall than individuals in a low felt presence environment. These results support the contention that due to felt presence, the on-site viewing experience leads to a more holistic perception of stimuli in comparison with television, which in turn enables arousal as a driver of the efficiency principle whereby the event and its sponsors are processed together (Kroeber-Riel, 1979). Therefore, increased arousal is expected to have a weaker negative impact on the recognition and recall of more congruent sponsors in an on-site than in a televisionmediated environment. Thus:

H2: In the context of a sports event with field sponsorship, the moderating effect of event-sponsor congruence on the negative relationship between arousal and sponsor recall and sponsor recognition is stronger in a television-mediated than in an on-site environment. 


\section{Method}

A field experiment was conducted using a regular season home game of the National Hockey League (NHL) franchise "Les Canadiens de Montréal". The objective was to compare the effectiveness of field sponsorship in the context of a sporting event (i.e., an ice hockey game) between an on-site (at the Bell Center, the arena of the team) and a mediated environments (on television) which, based on extant results from the literature, were expected to provide very different feelings of presence for the viewers. Recall and recognition of sponsors were measured among attendees and television viewers who watched the same game, at the same time, although in different environments (on-site versus on television). In order for the comparison to be meaningful, the sponsors examined had to be visible on-site as well as on television. This excluded the sponsors found only around the concession stands or around the arena's venue or the sponsors added to the television broadcast (i.e., logos superimposed on the game's images). As a consequence, the study focuses on the 31 sponsors found on the perimeter board around the ice as well as directly on the ice. The study was carried out with an industry partner that commercializes sponsorships for the Montréal hockey team and who helped the researchers to determine ahead of time which brands would be present and when on the signages when the game took place.

\section{Sample}

A total of 88 participants forming a convenience sample were randomly assigned to one of the two environment conditions. Their age ranged from 20 to 75 with a mean of $32 ; 39 \%$ were females whereas $61 \%$ were males (a proportion that reflects current audience figures for the NHL). In addition, $57 \%$ of them had completed a college education and $25 \%$ had a yearly income within the $\$ 40,000-\$ 60,000$ range $(67 \%$ earned below $\$ 60,000)$. The sample size $(n=44$ 
in each viewing environment) was deemed sufficient to detect differences between the two experimental conditions and to insure the effectiveness of the randomization procedure (Kerlinger and Lee, 2000).

\section{Procedure}

Professional hockey was selected as the sport context due to the great enthusiasm of Montréal's residents for their home team. Forty-four participants attended a home game between the Montréal's Canadians and the Washington Capitals in the arena whereas, at the same time, 44 other participants watched the same game on television. On-site attendees were offered free game tickets to participate whereas television viewers were offered $\$ 10$ as a compensation in exchange for participating in a sports marketing survey

When attending a sports event many factors can impact the extent to which each spectator is exposed to a given sponsor. Spectators' variables such as the distance from their seat to the sponsor's signages or, regardless of distance, spectators' seat position relatively to sponsors' signages can hinder the visibility of some sponsors whereas it can facilitate that of others. In addition, a given sponsor can purchase signage presence for 1, 2, or 3 time periods depending on its contract agreement. Therefore, some measures were taken in order to minimize the heterogeneity of sponsor exposure for spectators. First, the tickets offered to participants were of the same price $(\$ 100)$, given that price is strongly related to the distance between the seat and the ice and, hence, the sponsors' signage. These seats were located in the arena's "red" section which corresponds to a comfortable position to view the game and the sponsors (the distance from the ice is about the same as that of the VIP lounges). Second, the industry partner informed the researchers of the number of periods during which a given sponsor would be visible on the signage, allowing controlling for this factor in statistical analyses as exposure can influence 
memory outcomes (e.g., Walliser, 1996). Third, one of the researchers visited the arena and verified that the sponsors' signages had equal visibility irrespective of the seat location around the ice (for the seating zones of the participants).

In addition, because the company commercializing the sponsorships' rights of the Canadians' arena sells signs on the perimeter board around the ice by diagonally opposed pairs, the sponsors' disposition around the ice is symmetric. This disposition evens out differences in exposure to sponsors relatively to a given spectator's position in the arena. Also, the size of the sponsor's logo on the perimeter board was standard for each slot available. Finally, it is important to note that television viewers' exposure to the sponsors was the same as all participants in this condition watched the same broadcast at the same time.

Individual variables can also affect the ability to recall or recognize sponsors. Involvement with ice hockey was measured, since several studies have shown that spectators' involvement with a sport is related to sponsor's recognition (e.g., Lardinoit and Derbaix, 2001; Walliser, 1996; Walliser et al., 2005). Consumers' knowledge of the event was also measured because, as shown by Roy and Cornwell (2004), it can impact the information processing of sponsors (i.e., more thoughts are elicited among experts than novices) which can affect recall and recognition. Brand familiarity, corresponding to the amount of direct (i.e., usage) and indirect (e.g., word of mouth) experience consumers have had with a brand (Alba and Hutchinson, 1987), is an important determinant of information processing and was measured as well. Campbell and Keller (2003) have shown that more familiar brands necessitate more processing capacity, which can influence recall and recognition. Finally, age was measured as older spectators generally have lower sponsorship identification scores (Walliser, 1996; Walliser et al., 2005). 
On the day of the game, each participant received a "participant's kit" which contained two questionnaires. The first had to be filled in before and during the game. The before-the-game measures included the control variables, such as involvement with ice hockey, knowledge of the event, and demographic variables. The during-the-game measure was arousal, which was assessed after each of the game's three periods. This was done to ensure that the participants would not assess their arousal retrospectively, as this may have led them to focus on discrete events during the game (goals, fighting, etc.), which would not correspond to an assessment of their experience as a whole.

The second questionnaire was administered after the game. It was enclosed in a sealed envelope that participants were instructed not to open until after the game was over. It included measures of recall and recognition for each sponsor appearing during the game. In addition, brand familiarity and sponsor-event congruence were included in order not to prime respondents before they attended or watched the game. Respondents also had to indicate the date and time at which they filled in the questionnaire. Both questionnaires were picked up after the game at the participant's home or were sent to the researchers using a prepaid envelope.

\section{Measures}

Zaichkowsky's (1985) scale was adapted to measure involvement with ice hockey. Participants' previous knowledge of the sponsors was assessed by considering the number of hockey games they had attended at the Bell Center or watched on television up to that point in the season. Arousal was measured with a scale adapted from Mehrabian and Russell (1974) whereas brand familiarity was measured using one item from Kent and Allen (1994). Consistent with a conceptualization of event-sponsor congruence at on overall level, a measure was adapted from Speed and Thompson (2000) using the following three items: "There is a logical connection 
between the Montréal's Canadians and [sponsor X]”, “[Sponsor X] and the Montréal's Canadians fit well together", and "It makes sense to me that [sponsor X] sponsors the Montréal's Canadians". This is consistent with Olson and Thjømøe's (2011) choice of an overall measure of congruence to serve as a criterion in their study of congruence dimensions. The frequency of sponsors' appearance on the perimeter board (i.e., the number of periods of visibility purchased) was operationalized by a 3-point scale (all on ice sponsors were visible during the 3 periods). The recall measure consisted in asking the participants to list the names of the sponsors of the game they could remember in a top-of-mind fashion. Following this, the participants had to circle the names of the brands that they recognized as being the actual sponsors of the game from a list that included real sponsors (31) as well as foils (16). Consumer knowledge of the event was operationalized with two measures. The first required respondents to indicate the number of games of the Canadians they had attended to so far this season at the Bell Center whereas the second asked them to indicate the number of games of the Canadians they had watched on television so far.

\section{Statistical analyses}

Each participant recalled or did not recall, and recognized or did not recognize each of the 31 sponsors. The 31 binary scores for recall and recognition were therefore analyzed using a multiple logistic regression model for correlated data (Hosmer and Lemeshow, 2000). Recall and recognition were analyzed separately. The main effects of environment, arousal, event-sponsor congruence, and their two and three-way interactions were all included in the model to test the research hypotheses. In addition, the control variables enumerated above were included as covariates (age, brand familiarity, sponsor exposure frequency, involvement with ice hockey and consumer knowledge of the event at the Bell Center and on television). A generalized estimating 
equation (GEE) method was used to estimate the model parameters, with a logit link function and an exchangeable working correlation matrix to take into account the within-participant association between the 31 binary responses (these logistic regression analyses with correlated data were performed with the procedure GENMOD in SAS, version 9.2 for Windows).

\section{Results}

The multi-item scales (involvement with ice hockey, event-sponsor congruence, and arousal) were assessed for dimensionality as well as reliability. They were all psychometrically sound (range of percentage of variance explained by the first factor extracted: 58\%-97\%; all Cronbach's alphas $>0.93$ ). Because the mean of several measures is more stable than a single measure taken at one point in time, arousal scores were operationalized by averaging the scores of the three measures taken after each period. The correlations among the three measures of arousal were strong (Cohen, 1992), positive, and statistically significant (average correlation $=$ 0.55). All of the participants answered the second questionnaire within 24 hours after the end of the game. A multiple linear regression model using 'hours since game ended" as a dependent variable and environment, arousal, as well as their interaction, as independent variables was not statistically significant $(F(3,83)=1.65, p=.19)$, which indicated that time elapsed since exposure to sponsors was not a factor influencing memory. In addition, there was no difference on average for the individual variables between the participants who watched the game at the Bell Center and on television, except for the number of games attended at the Bell Center which was higher for participants who were randomly assigned to watch the game on-site (see Table I).

\section{[Insert Table I about here]}

Participants at the Bell Center recalled on average $17.6 \%$ of sponsors and recognized $33.0 \%$ of them compared to $14.8 \%$ and $28.9 \%$ for those who watched the game on television. Recall 
scores for the focal sponsors ranged from 0 to $55 \%$ whereas recognition scores ranged from 0 to $81 \%$ (with foil recognition scores ranging from 0 to $23 \%$ ). All participants filled in both questionnaires. The parameter estimates of the logistic regression model for recall and recognition are displayed in Table II. As expected, sponsor exposure frequency during the game, brand familiarity, involvement with ice hockey as well as consumer knowledge of the event acquired from previous game attendance at the Bell Center all had a statistically significant impact on sponsor recall and recognition. However, contrary to what was expected, consumer knowledge of the event acquired from watching previous games on television did not impact recall or recognition significantly $(p>0.05)$.

\section{[Insert Table II about here]}

\section{Tests of the research hypotheses}

There was a main negative effect of arousal on recognition $(\mathrm{B}=-0.31, \mathrm{z}=-2.41, p=0.02)$ and a nearly significant effect of arousal on recall in the same direction $(\mathrm{B}=-0.18, \mathrm{z}=-1.70, p=$ 0.089), which provided evidence in support of H1a. This main effect was qualified by a two-way interaction between arousal and congruence which was negative and statistically significant for both recall $(\mathrm{B}=-0.12, \mathrm{z}=-2.09, p=0.04)$ and recognition $(\mathrm{B}=-0.08, \mathrm{z}=-2.09, p=0.04)$. Consistent with $\mathrm{H} 1 \mathrm{~b}$, the detrimental effect of arousal intensity on sponsor identification was stronger among the more congruent event-sponsor pairs. This result was further qualified by a significant three-way interaction between arousal, congruence, and environment for both recall $(\mathrm{B}=0.15, \mathrm{z}=2.09, p=0.04)$ and recognition $(\mathrm{B}=0.10, \mathrm{z}=1.93, p=0.05)$. To better understand the nature of these three-way interactions, the estimated odds ratios, with their 95\% confidence intervals, for recall and recognition of a sponsor, were computed at different levels of arousal and congruence among spectators at the Bell Center and those research participants watching the 
game on television (i.e., the effect of viewing environment). These results are displayed in Table III.

\section{[Insert Table III about here]}

Recall results show that, as congruence increased, a low arousal (level $=3$ on a 7 -point scale) had a stronger detrimental effect in the on-site environment than in the television

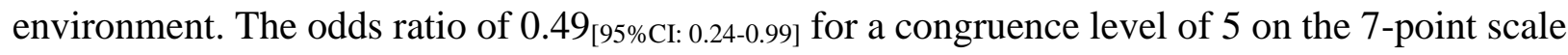
indicates that the odds of recalling a given sponsor versus not recalling it are about half in the arena of what they are in the context of television viewing. This odds ratio trend continues progressively as congruence increases with the odds of on-site recall dipping to one-fourth of those in the television environment when congruence reaches 7 (Congruence Level: $6=0.36$ [95\%CI: 0.15-0.87]; Congruence Level: $7=0.27$ [95\%CI: 0.09-0.81]). As arousal intensified, the negative impact of congruence on-site relative to television weakened. When arousal is at level 4 , it is only in the case of the highest congruence level (7) that the on-site odds are lower than the television odds (odds ratio $=0.50$ [95\%CI: 0.26-0.99). When arousal is at a middle-ground value (level 5), congruence does not influence the on-site recall odds relatively to television with ratios close to 1 at every level. At arousal level 6, congruence heightens the recall odds ratios with values above 1 from level 4 on, in a reversed pattern compared to lower arousal values, although this effect did not reach statistical significance. This new trend accentuates when arousal peaks at level 7, as higher congruence strengthens the odds ratios up to on-site odds being 3 times as large as television odds (Congruence Level: $7=3.41$ [95\%CI: 1.08-10.68]). These results are presented in terms of recall probabilities in Figures 1a and 1b. As can be seen, the estimated probability of recall in the television environment diminishes drastically as arousal intensifies at higher congruence levels (e.g., from 0.35 at arousal $=1$ to 0.05 at arousal intensity $=7$ for congruence $=7$ ). However, the 
on-site recall probability increases with arousal when congruence becomes stronger albeit to a much lesser extent in comparison with the decrease observed in the television environment. This is consistent with $\mathrm{H} 2$ according to which the negative impact of the combined effects of arousal and congruence on recall is stronger in the television environment than on-site due to weaker feelings of presence in the former environment that promote an intensity rather than an efficiency mode of processing.

[Insert Figures $1 \mathrm{a}, 1 \mathrm{~b}$ and 2a, 2b about here]

The pattern of recognition results is similar to that for recall, although the different impact of congruence as a function of arousal on-site compared to television is even more acute. At a low level of arousal (level 3), the odds ratio drops below 1 from congruence levels 4 to 7 in contrast to a similar drop with recall data from congruence levels 5 to 7 (Congruence Level: $4_{4}=0.46$ [95\%CI: 0.22-0.96]; Congruence Level: $5=0.36$ [95\%CI: 0.16-0.78]; Congruence Level: $6=0.28$ [95\%CI: 0.11-0.67]; Congruence Level: $7=0.21$ [95\%CI: 0.08-0.68]). This trend does not weaken as much at arousal level $=4$ compared to recall since congruence still impedes more strongly on-site recognition than television recognition from levels 5 to 7 (Congruence Level: $5=0.57_{\text {[95\%Cr: } 0.33-0.96 \text { ]; Congruence }}$ Level: $6=0.49$ [95\%CI: 0.27-0.89]; Congruence Level: $7=0.42$ [95\%CI: 0.21-0.84]). As arousal keeps intensifying, the pattern of results is exactly the same as for recall with the start of the reversal trend. Odds ratios are very close to 1 at arousal level 5 and they are increasing at arousal level 6 when congruence strengthens (although still not reaching statistical significance). Then, at peak arousal, results are fully reversed, as it was observed with recall, although from congruence levels 5 to 7 rather than at congruence level 7 only in the case of recall (Congruence Level: $5=2.33$ [95\%CI: 1.06-5.11]; Congruence Level: $6=2.71$ [95\%CI: 1.22-6.04]; Congruence Level: $7=3.16$ [95\%CI: 1.32-7.58]). Hence, the recognition results are the same as those observed with recall, although in a more 
vivid fashion as illustrated in Figure $2 \mathrm{a}$ and $2 \mathrm{~b}$. These results are also consistent with $\mathrm{H} 2$ and support the proposed theoretical rationale developed according to which the greater presence felt on-site fosters the cognitive resources allocated to the sponsors by tipping processing toward the efficiency rather the intensity principle.

Additional analyses were performed to rule out alternative explanations for these results. Although the level of involvement with ice hockey was controlled in the model, it could be that respondents in the on-site condition were more involved with the team since they had the opportunity to watch a home game. Hence, another model was run which was identical to the previous ones with the exception that the two-way interaction between environment and involvement with ice hockey was added as a predictor. The results showed that the additional parameter estimate was not statistically significant, neither for recall nor for recognition ( $z$ values $<0.11, p$ values $>0.91)$. Therefore, the results and interpretations associated with the hypothesis testing procedure remain unchanged.

\section{Discussion}

Sponsorship's impact on consumers' memory is a critical dimension of overall sponsorship effectiveness (Cornwell et al., 2006; Johar et al., 2006; Wakefield et al., 2007; Walliser et al., 2005). It is a coveted sponsorship outcome due to the importance of creating a strong association between the event and the sponsors (Cornwell and Humphreys, 2013; Meenaghan and O’Sullivan, 2013) as well as the strong positive influence of sponsor identification on the purchase of the sponsor's products (e.g., McDaniel, 1999; Wakefield and Bennett, 2010). In that regard the present study shows that, when examined in light of spectators' arousal state and event-sponsor congruence, the different degrees of felt presence inherent to each viewing environment plays an essential role in sponsors' recall and recognition. The results of this field 
experiment first confirm the negative influence of arousal on sponsor identification (e.g., Newell et al., 2001; Pavelchak et al., 1988), especially for congruent sponsors. To illustrate, a close, highly contested game, or competition, in which evenly matched opponents are unable to take a decisive lead until the very end offers the worst scenario for congruent sponsors due to higher arousal levels when the event is suspenseful (Bee and Madrigal, 2012). On the other hand, if one team, or one competitor, clearly outclasses its opponent from the very beginning, the results of this study suggest that sponsor identification would be much less hampered. Furthermore, the results revealed a memory advantage, for both recall and recognition, in the Bell Center compared to the television environment when arousal was elevated as event-sponsor congruence increased. Hence, arousal is particularly detrimental to congruent sponsor identification for consumers viewing the game in a low presence, mediated environment. A more detailed investigation of the difference between the high and low presence viewing contexts showed that the latter offers a better identification of congruent sponsors than the former at low levels of arousal whereas the reverse was true at higher levels of arousal. In essence, the interaction between congruence and environment reverses completely as arousal goes from a low to a high level.

These results are in line with the conceptual framework developed based on the role of 'felt presence' across different viewing environments and how it impacts the manner with which information about sponsors is processed. In keeping with the intensity principle of processing, elevated arousal leads to more focused and concentrated consumer information processing primarily on the stimulus that mainly triggers the arousal (i.e., the event), at the expense of the peripheral stimuli (i.e., the sponsors) (Pavelchak et al., 1988). This effect is compounded for event congruent sponsors since they do not benefit from the same depth of processing than 
incongruent ones (Mandler, 1982). However, because sponsors are better weaved into consumers' experience on-site than on television, they are less likely to be considered peripheral to the main stimulus in this viewing environment in which the efficiency principle of arousal is more dominant. Hence, in this case, the identification of congruent sponsors is not as impeded when arousal increases.

At low arousal levels however, the congruence of sponsors was more detrimental on-site than on television. Although this was not explicitly addressed in the conceptual framework (a larger detrimental impact of congruence was expected on-site as arousal strengthens), this result can be explained by noting that neither the processing efficiency nor the intensity principle are at play when arousal is low. While increased arousal can foster either the efficiency or the intensity of processing (Cornwell et al., 2005), at low arousal levels neither of them applies to information processing. As a result, in such a situation the processing of sponsors is likely to be determined by other factors, such as potential distractors in the environment of the event. It seems likely that an on-site experience offers a great deal of stimulation beyond the event itself. Hence, when arousal is low, presumably because the event is not particularly riveting, viewers' attention may wander easily due to distractors unrelated to the event or the sponsors, such as people next to them or in the arena. Viewers of the television broadcast however are likely to focus their attention on the TV screen even when arousal is low, because this is where the game is taking place. As a result, the processing of congruent sponsors should be less hampered at low arousal levels for television viewers than for game attendees. This explanation is consistent with the 'felt presence' conceptual framework; television viewers are immersed in an environment that does not offer as many distractions as 'being there' when arousal is low (i.e., when neither the efficiency nor the intensity principle is at play). 


\section{Managerial implications}

One important finding uncovered in this study is that the drama component of a game - that is, the intensity of the game's emotional content and the arousal it generates (Cummins et al., 2012; Mason, 1999) - adversely impacts the recall and recognition of its sponsors, particularly among congruent ones. In addition, as arousal intensifies, on-site recall and recognition results outperform those observed in a mediated environment, such as a television broadcast, presumably due to weak feelings of presence. These results convey important implications for practitioners, from the point of view of those responsible of organizing sports events that are attractive for sports fans as well as from that of potential sponsors, and that of sponsorship managers who want to maximize sponsorship benefits for their brand.

In the first case, the findings of this study highlight a dilemma for marketers: as arousal and drama are often the main reasons attracting sports event spectators (Cummins et al., 2012; Hirt and Clarkson, 2011), they must also consider the impact of high arousal levels on sponsor identification, especially for congruent sponsors which are often the core constituents of sponsorship revenues. Thus, while the efforts invested by different professional sports leagues to create a leveled field of competition (Cummins et al. 2012; Quirk and Fort, 1997) such as enforcing a salary cap, implementing draft systems, and having open leagues (where the bottom ranked teams in a given league are downgraded to less prestigious leagues) contribute to maintain interest through higher arousal, the results of this study suggest that they may not be optimal as regard sponsor identification, a significant indicator of sponsorship effectiveness. In the case of high-frequency sponsored sports events, such as the North American professional ice hockey league games studied herein, a solution might be to hold events with various arousing potential for spectators. Exhibition, charity, or pre-season games often have low stakes and could 
be relied on more heavily in order to yield better sponsor identification. Although professional teams often play in games such as these, they tend to be lumped together, at the beginning of the season for instance. Interspersing low stakes games throughout the season amid higher stakes games should therefore be considered in order to maximize sponsor identification benefits. In addition, this is in line with memory research having shown that spaced repetition facilitates learning to a greater extent than extensive rehearsal at one point in time. More specifically, stimulus memory is significantly enhanced with increasing time intervals between exposures (Greene, 2008). Hence, low stakes games scheduled at increasingly longer intervals during the course of a season could enhance sponsor identification by providing better exposure conditions due to a low arousal context.

The results of this research also have implications for sponsorship managers. If the sponsoring brand's objective is to improve recall and recognition among the widest possible audience, using field sponsorship in the context of low stakes games (i.e., low arousal) is probably the best strategy because it maximizes congruent sponsor identification among the audience in a mediated viewing experience. This strategy would be particularly interesting in the case of a mass appeal sports brand that needs to build up its awareness among all potential customers. On the other hand, if the objective is to optimize sponsor identification among the on-site audience, higher stakes games appear to be more suitable. This could be the strategy pursed by brands specialized in marketing sporting goods that are consistent with the activity displayed at the event (e.g., ice hockey).

\section{Limitations and avenues for further research}

As mentioned earlier, this field experiment was carried out in the context of a regular season game. Because research has shown that the relationship between arousal and recall is probably 
not linear (e.g., Tavassoli et al., 1995), it would be relevant to test the interplay between viewing environment (and, consequently, felt presence), sponsor-event congruence, and arousal in the context of high stakes sporting events (e.g., a playoff or a Stanley Cup game). High stakes games are notoriously unpredictable, to the extent that seasoned gamblers strategically shun them (d'Astous and Di Gaspero, 2013). In turn, the unpredictability of a high stakes game stimulates arousal as empirically shown by Humphreys (2002) and Walliser (1996). In fact, any factor that increases the unpredictability of the outcome of a sporting event is likely to affect sponsor recall and recognition due to the influence of arousal (Cummins et al., 2012). For instance, high scoring intensity sports (e.g., basket-ball) might generate more arousal than low scoring intensity sports (e.g., soccer) and, hence, would offer to sponsors a more favorable on-site watching environment relative to television viewing. In line with this observation, close games in which the outcome is not known until the very end are also likely to generate more arousal (Humphreys, 2002). In sum, further research could investigate the role of game stakes, scoring intensity, and scoring gap in sponsorship recall and recognition.

In addition, sporting events spectators differ regarding their dominant interest in watching and following sports (Hirt and Clarkson, 2011). Some consumers are in search of arousing, potent emotions whereas others are mostly pursuing positive emotions hoping that their favorite team or players will be successful; regardless of the arousing capacity of the game (Mumford, 2011). This distinction underscores the two main dimensions of emotional responses to sporting events, namely arousal and valence (Bal et al., 2011). Sponsorship effectiveness could differ across spectators seeking either arousing or positive emotions. Thus, future studies could investigate whether it is possible to distinguish between these two approaches to spectatorship among game attendees and whether they show different patterns of response to sponsors' signages and 
activations. It should be noted however that, contrary to arousal, emotional valence is typically not conceived as a significant driver of memory. Empirical evidence supporting the influence of emotional valence on ad recall is weak at best (e.g., Pavelchak et al., 1988; Shapiro et al., 2002). As a consequence, while studies should investigate further the relationship between arousal and memory, future research endeavors encompassing both arousal and valence should examine the influence of this later component on more affect-laden outcomes, such as attitudinal responses.

The limitations of this study offer interesting research opportunities. Some are related to the generalization of the results. Because the comparison of on-site and television viewing was done in a single sport context, it would be important to validate the findings in other sports disciplines. Different spectator sports could be used such as soccer, football, or basketball. It would be worthwhile also to consider sports games where spectators are not rooting specifically for either team - contrary to the context of this study -, such as a soccer World Cup game in which one's national team is not playing. Furthermore, participant sports could yield different results in comparison with spectator sports such as ice hockey. The degree of involvement is often greater in the former events since participants may use some of the sponsors' products during the event. For instance, runners in the New York marathon may be more or less influenced by sponsors than spectators following it online or on television.

It should be also noted that in this study event-sponsor congruence was observed. In future studies, congruence should be manipulated to better assert its effects. This could allow accounting for the different degrees of exposure that congruent and incongruent sponsors benefit from during a television broadcast in order to more firmly establish the relative recall and recognition performances in an on-site compared to a mediated environment. 
In addition, in this study on-site viewing was compared with one type of mediated environment (i.e., television) to the extent that past research has unambiguously demonstrated that the latter instills milder feelings of presence. However, as advanced television technologies such as 3D HDTV (Grigorovici, 2003) become more widespread, the felt presence gap with real environments is likely to progressively close. Hence, future investigations of the processing differences across on-site and television viewing environments as a function of arousal are warranted. In the same vein, future studies should consider other media where the viewing experience might be more or less conducive to feelings of presence (such as the Internet or radio), in comparison with television, in order to investigate sponsorship stimuli processing in these contexts as well.

It is also important to note that arousal was measured at three points in time during the game and that the mean of these three measures was used as the arousal score for each participant. Although averaging several measures provides a more stable assessment of arousal than a single measure at one point in time, this can also hide some potentially different arousal patterns. For instance, for a comparable average arousal level it could be that one participant's arousal peaks very high and then drops whereas another participant's arousal would be constant over time. It is worth emphasizing however that there was a strong, positive, and statistically significant correlation among the three measures of arousal; hence mitigating the possibility that arousal variability during the game was a factor influencing the processing of sponsors beyond that of overall arousal.

Finally, the long-term differential impact of on-site versus mediated viewing experience should be examined. Research to determine whether the benefits of repetitive exposure to the same sponsors accumulate faster in one environment than in the other would be especially 
useful. It could be that learning, just like processing mode, depends on the feelings of presence triggered by the type of environment in which sponsorship stimuli are presented. 


\section{References}

Alba, J.W. and Hutchinson, J.W. (1987), "Dimensions of consumer expertise", Journal of Consumer Research, Vol.13 No.4, pp. 411-54.

Bal, C., Quester, P. and Plewa, C. (2010), "Emotions and sponsorship a key to global effectiveness? A comparative study of Australia and France", Asia Pacific Journal of Marketing and Logistics, Vol. 22 No.1, pp. 40-54.

Bee, C.C. and Madrigal, R. (2012), "It's not whether you win or lose; it's how the game is played the influence of suspenseful sports programming on advertising", Journal of Advertising, Vol.41 No.1, pp. 47-58.

Bennett, R. (1999), "Sport sponsorship, spectators recall and false consensus", European Journal of Marketing, Vol.34 No.3/4, pp. 291-313.

Campbell, M.C. and Keller, K.L. (2003), "Brand familiarity and advertising repetition effects", Journal of Consumer Research, Vol. 30 September, pp. 292-304.

Carrillat, F.A., Harris, E.G. and Lafferty, B.A. (2010), "Fortuitous brand image transfer: Investigating the side effect of concurrent sponsorships", Journal of Advertising, Vol. 39 No.2, pp. 109-23.

Carrillat, F.A. and d'Astous, A. (2012), "The sponsorship-advertising interface: Is less better for sponsors?", European Journal of Marketing, Vol.46 No. 3, pp. 562-674.

Carrillat, F.A., d'Astous, A. and Davoine, V. (2013), "The sponsor-event geographical match as a dimension of event-sponsor fit: An investigation in Europe and North America", Australasian Marketing Journal, Vol. 21 No. 4, pp. 264-70.

Cathelas, B. (1999), La soif d'émotions, Plon, Paris.

Cohen, J. (1992), "A power primer", Psychological Bulletin, Vol. 112 No. 1, pp. 155-59.

Collins, A.M. and Loftus, E.F. (1975), "A spreading-activation theory of semantic processing", Psychological Review, Vol. 82 No. 6, pp. 407-28.

Cornwell, T. B. and Humphreys, M. S. (2013), "Memory for sponsorship relationships: A critical juncture in thinking", Psychology \& Marketing, Vol. 30 No. 5, pp. 394-407.

Cornwell, T.B., Humphreys, M.S., Maguire, A.M., Weeks, C.S. and Tellegen, C.L. (2006), "Sponsorship-linked marketing: The role of articulation in memory", Journal of Consumer Research, Vol. 33 No. 3, pp. 312-21.

Cornwell, T.B., Weeks, C.S. and Roy, D.P. (2005), "Sponsorship-linked marketing: Opening the black box", Journal of Advertising, Vol. 34 No. 2, pp. 21-42. 
Cummins, R.G., Keene, J.R. and Nutting, B.H. (2012), "The impact of subjective camera in sports on arousal and enjoyment", Mass Communication and Society, Vol. 15 No. 1, pp. 7497.

d'Astous, A. and Di Gaspero, M. (2013), "Explaining the performance of online sports bettors", International Gambling Studies, Vol. 13 No. 3, pp. 371-87.

d'Ydewalle, G., Abeele, P.V., Rensbergen, J.V. and Coucke, P. (1988), "Incidental processing of advertisements while watching soccer games broadcasts", in Gruneberg, M., Morris, P. and Sykes, R. Eds., Practical aspects of memory : Current research and issues, John Wiley \& Sons, Oxford, England. pp. 478-83.

Dekhil, F. (2010), "The effects of the type of audience, involvement, interest and sociodemographic variables on sponsor recall: The soccer African Nations Cup", International Journal of Sports Marketing \& Sponsorship, Vol. 11 No. 2, pp. 158-75.

Edwards, S. M. and Gangadharbatla, H. (2001), "The novelty of 3D product presentations online", Journal of Interactive Advertising, Vol. 1 No. 2, pp. 10-18.

Fleck, N. and Quester, P. (2007), "Birds of a feather flock together... Definition, role and measure of congruence; an application to sponsorship", Psychology \& Marketing, Vol. 24 No. 11, pp. 975-1000.

Grigorovici, D. (2003), "Persuasive effects of presence in immersive virtual environments", in Riva, G., Davide, F. and IJsselsteijn, W.A. (eds.), Being there: Concepts, effects and measurement of user presence in synthetic environments, IOS Press, Amsterdam, The Netherlands.

Greene, R.L. (2008), "Repetition and spacing effects", in Roediger, H.L.III. Ed., Learning and memory: A comprehensive reference, Elsevier, Oxford. pp. 65-78.

Greenwald, A.G. and Leavitt, C. (1984), "Audience involvement in advertising: Four levels", Journal of Consumer Research, Vol. 11 June, pp. 581-92.

Hatada, T., Sakata, H. and Kusaka, H. (1980), "Psychophysical analysis of the "sensation of reality" induced by a visual wide-field display", SMPTE Journal Vol. 89, pp. 560-69.

Heeter, C. (2003), "Reflections on real presence by a virtual person", Presence: Teleoperators and Virtual Environments, Vol. 12 No. 4, pp. 335-45.

Hirt, E.R. and Clarkson, J.J. (2011), "The psychology of fandom: Understanding the etiology, motives and implications of fanship", in Kahle, L.R. and Close, A.G. Eds., Consumer behavior knowledge for effective sports and event marketing, Taylor \& Francis Group, New York, NY. pp. 59-86.

Hosmer, D.W. and Lemeshow, S. (2000), Applied logistic regression, John Wiley \& Sons, Hoboken, NJ. 
Humphreys, B.R. (2002), "Alternative measures of competitive balance in sports leagues", Journal of Sports Economics, Vol. 3 No. 2, pp. 133-48.

IJsselsteijn, W. A., Ridder, H. d., Freeman, J. and S. Avons. (2000), "Presence: Concept, determinants and measurement", in Photonics West - Human Vision and Electronic Imaging Conference, San Jose, CA.

IJsselsteijn, W., Riddera, H. d., Hamberga, R., Bouwhuisa, D. and Freeman, J. (1998), "Perceived depth and the feeling of presence in 3DTV", Displays, Vol. 18 pp. 207-14

Jagre, E., Wilson, J.J. and Watson, J.G. (2001), ""Sponsorship and congruity theory: A theoretical framework for explaining consumer attitude and recall of event sponsorship", in Proceedings of the Association for Consumer Research, Valdosta, GA, pp. 439-44.

Johar, G. V., Pham, M. T. and Wakefield, K. L. (2006), "How event sponsors are really identified: A (baseball) field analysis", Journal of Advertising Research, Vol. 46 No. 2, pp. 183-98.

Keller, K.L. (1993), "Conceptualizing, measuring, and managing customer-based brand equity", Journal of Marketing, Vol. 57 No. 1, pp. 1-22.

Kent, R.J. and Allen, C.T. (1994), "Competitive interference effects in consumer memory for advertising: The role of brand familiarity", Journal of Marketing, Vol.58 No. 3, pp. 97-105.

Kerlinger, F.N. and Lee, H.B. (1986), Foundations of behavioral research, Thompson Learning, Stamford, CT.

Ko, Y. J., Zhang, J., Cattani, K. and Pastore, D. (2011), "Assessment of event quality in major spectator sports", Managing Service Quality, Vol. 21 No. 3, pp. 304 - 22.

Kroeber-Riel, W. (1979), "Activation research: Psychobiological approaches in consumer research", Journal of Consumer Research, Vol. 5 March, pp. 245-50.

Lardinoit, T. and Derbaix, C. (2001), "Sponsorship and recall of sponsors", Psychology \& Marketing, Vol. 18 No. 2, pp. 167-90.

Lardinoit, T. and Quester, P.G. (2001), "Attitudinal effects of combined sponsorship and sponsor's prominence on basketball in Europe", Journal of Advertising Research, Vol. 41 No. 1, pp. 48-58.

Li, H., Daugherty, T. and Biocca, F. (2002), "Impact of 3-d advertising on product knowledge, brand attitude, and purchase intention: The mediating role of presence", Journal of Advertising, Vol. 31 No. 3, pp. 43-57.

Lombard M. and Ditton, T. (1997), "At the heart of it all: The concept of presence", Journal of Computer Mediated Communication, Vol. 3 No. 2. 
Mandler, G. (1982), "The structure of value: Accounting for taste", in Clark, M.S. and Fiske, S.T. Eds., Affect and cognition: The 17th annual carnegie symposium, Lawrence Erlbaum Associates, Hillsdale, NJ. pp. 203-30.

Mason, D.S. (1999), "What is the sports product and who buys it? The marketing of professional sports leagues", European Journal of Marketing, Vol. 33 No. 3/4, pp. 402-18.

Mazodier, M. and Merunka, D. (2012), "Achieving brand loyalty through sponsorship: The role of fit and self-congruity", Journal of the Academy of Marketing Science, Vol. 40 No. 6, pp. 807-20.

McDaniel, S.R. (1999), "An investigation of match-up effects in sport sponsorship advertising: The implications of consumer advertising schemas", Psychology \& Marketing, Vol. 16 No. 2, pp. 163-84.

Nicovich, S.G. (2005), "The effect of involvement on ad judgment in a video game environment: The mediating role of presence", Journal of Interactive Advertising, Vol. 6 No. 1, pp. 38-51.

Meenaghan, T. and O’Sullivan, P. (2013), "Metrics in sponsorship research-is credibility an issue?", Psychology \& Marketing, Vol. 30 No. 5, pp. 408-16.

Mehrabian, A. and Russell, J.A. (1974), An approach to environmental psychology, The MIT Press, Cambridge, MA.

Mumford, S. (2012), Watching sport: Aesthetics, ethics and emotion, Routledge, New-York, NY.

Nebenzahl, I. and Hornik, J. (1985), "An experimental study of the effectiveness of commercial billboards in televised sports arenas", International Journal of Advertising, Vol. 4 No.1, pp. 27-36.

Newell, S., Henderson, K.V. and Wu, B.T. (2001), " The effects of pleasure and arousal on recall of advertisements during the super bowl", Psychology \& Marketing, Vol. 18 No. 11, pp. 1135-51.

Ngan, H.M.K., Prendergast, G.P. and Tsang, A.S.L. (2011), "Linking sports sponsorship with purchase intentions: Team performance, stars, and the moderating role of team identification", European Journal of Marketing, Vol. 45 No. 4, pp. 551-66.

Nicholls, J.A.F., Roslow, S. and Dublish, S. (1999), "Brand recall and brand preference at sponsored golf and tennis tournaments", European Journal of Marketing, Vol. 33 No. 3/4, pp. 365-86.

Olson, E.L. (2010), "Does sponsorship work in the same way in different sponsorship contexts?", European Journal of Marketing, Vol. 44 No. 1/2, pp. 180-99. 
Olson, E.L. and Thjømøe, H.M. (2009), "Sponsorship effect metric: Assessing the financial value of sponsoring by comparisons to television advertising", Journal of the Academy of Marketing Science, Vol. 37 No. 4, pp. 504-15.

Olson, E.L. and Thjømøe, H.M. (2011), "Explaining and articulating the fit construct in sponsorship", Journal of Advertising, Vol. 40 No. 1, pp. 57-40.

Pavelchak, M.A., Antil, J.H. and Munch, J.M. (1988), "The Superbowl: An investigation into the relationship among program context, emotional experience, and ad recall", Journal of Consumer Research, Vol. 15 No. 3, pp. 360-67.

Pham, M.T. (1992), "Effects of involvement arousal and pleasure on the recognition of sponsorship stimuli", in Advances in Consumer Research, ACR, Provo, UT, pp. 85-93.

Pham, M.T. and Vanhuele, M. (1997), "Analyzing the memory impact of advertising fragments", Marketing Letters, Vol. 8 No. 4, pp. 407-17.

Pope, N.K.L. and Voges, K.N. (1997), "An exploration of sponsorship awareness by product message location in televised sporting events", The Cyber-Journal of Sport Marketing, No. 1 Vol. 1, pp. 16-27.

Prendergast, G.P., Poon, D. and West, D.C. (2010), "Match game linking sponsorship congruence with communication outcomes", Journal of Advertising Research, Vol. 50 No. 2, pp. 214-26.

Prothero J. and Hoffman, H. (1995), "Widening the field of view increases the sense of presence", HITLab Technical, Report R-95-5.

Prothero, J. D., Hoffman, H. G., Parker, D. E., III, T. A. F. and Wells, M. J. (1995)," Foreground/background manipulations affect presence", Proceedings of the Human Factors and Ergonomics Society 39th Annual Meeting, Santa Monica, CA.

Quester, P. (1997), "Awareness as a measure of sponsorship effectiveness - the adelaide formula one grand prix", Journal of Marketing Communications, Vol. 3 No. 2, pp. 1-20.

Quirk, J. and Fort, R.D. (1997), Pay dirt: The business of professional team sports, Princeton University Press, Princeton, NJ.

Reid, L.A. (1970), "Sport, the aesthetic and art", British Journal of Educational Studies, Vol. 18 No. 3, pp. 245-58.

Roy, D.P. and Cornwell, T.B. (2004), "The effects of consumer knowledge on responses to event sponsorships", Psychology \& Marketing, Vol. 21 No. 3, pp. 185-207.

Shapiro, S., Maclnnis, D. J. and Park, C. W. (2002), "Understanding program-induced mood effects: Decoupling arousal from valence", Journal of Advertising, Vol. 31 No. 4, pp. 15-26. 
Sheridan, T.B. (1992), "Musings on telepresence and virtual presence", Presence, Vol. 1 No. 1, pp. 120-26.

Simmons, C.J. and Becker-Olsen, K.L. (2006), "Achieving marketing objectives through social sponsorships", Journal of Marketing, Vol. 70 October, pp. 154-69.

Speed, R. and Thompson, P. (2000), "Determinants of sports sponsorship response", Journal of the Academy of Marketing Science, Vol. 28 No. 2, pp. 226-38.

Stangor, C. and McMillan, D. (1992), "Memory for expectancy-congruent and expectancyincongruent information: A review of the social and social developmental literatures", Psychological Bulletin, Vol. 111 No. 1, pp. 42-61.

Tavassoli, N.T., Shultz, C.J.I. and Fitzsimons, G.J. (1995), "Program involvement: Are moderate levels best for ad memory and attitude toward the ad?", Journal of Advertising Research, Vol. 35 No. 5, pp. 61-72.

Tripodi, J.A., Hirons, M., Bednall, D. and Sutherland, M. (2003), "Cognitive evaluation: Prompts used to measure sponsorship awareness", International Journal of Market Research, Vol 45. No. 4, pp. 435-55.

Turley, L.W. and Shannon, J.R. (2000), "The impact and effectiveness of advertisements in a sports arena", Journal of Services Marketing, Vol 14 No. 4, pp. 323-36.

Usoh, M., Catena, E., Arman, S. and Slater, M. (2000), "Using presence questionnaires in reality", Presence: Teleoperators \& Virtual Environments, Vol. 9 No. 5, pp. 497-503.

Wakefield, K. L. and Bennett, G. (2010), "Affective intensity and sponsor identification", Journal of Advertising, Vol. 39 No. 3, pp. 99-111.

Wakefield, K.L., Becker-Olsen, K. and Cornwell, T.B. (2007), "I spy a sponsor", Journal of Advertising, Vol 36. No.4, pp. 61-74.

Walliser, B. (1996), "Le rôle de l'intensité des émotions éprouvées par le téléspectateur dans la mémorisation du parrainage ", Recherche et Applications en Marketing, Vol. 11 No. 1, pp. $5-22$.

Walliser, B., Kacha, M. and Mogos-Descotes, R. (2005), "Legitimizing public authorities as sponsors: An inquiry into the factors, related to the perception and memorization of their sponsorship", International Review on Public and Non Profit Marketing, Vol. 2 No. 1, pp. $51-58$.

Wyer, R.S.J. and Carlston, D.E. (1979), Social cognition, inference, and attribution, Erlbaum Associates, Hillsdale, NJ.

Zaichkowsky, J.L. (1985), "Measuring the involvement construct", Jounal of Consumer Research, Vol. 12 No. 3, pp. 341-52. 


\section{Table I.}

Descriptive statistics of individual control variables for participants who watched the hockey game on-site at the Bell Center versus on television.

\begin{tabular}{|c|c|c|c|c|c|}
\hline \multirow[b]{3}{*}{ Variables } & \multicolumn{4}{|c|}{ Environment } & \multirow{3}{*}{$p$-value ${ }^{1}$} \\
\hline & \multicolumn{2}{|c|}{$\begin{array}{l}\text { Bell Center } \\
\quad(n=44)\end{array}$} & \multicolumn{2}{|c|}{$\begin{array}{c}\text { Television } \\
(n=44)\end{array}$} & \\
\hline & Mean & STD & Mean & STD & \\
\hline Age & 33.9 & 15.0 & 30.1 & 13.2 & 0.2165 \\
\hline $\begin{array}{l}\text { Involvement with ice } \\
\text { hockey }\end{array}$ & 4.7 & 1.4 & 4.5 & 1.0 & 0.4515 \\
\hline $\begin{array}{l}\text { Number of games attended } \\
\text { on-site }\end{array}$ & 2.1 & 1.5 & 0.6 & 0.8 & $<0.0001$ \\
\hline $\begin{array}{l}\text { Number of viewing games } \\
\text { on television }\end{array}$ & 15.6 & 14.8 & 20.5 & 14.7 & 0.1248 \\
\hline Arousal & 5.2 & 1.1 & 4.9 & 0.9 & 0.3264 \\
\hline Gender - \% male & $57 \%$ & & $65 \%$ & & 0.3812 \\
\hline Congruence $^{2}$ & 4.1 & 1.9 & 4.0 & 1.8 & 0.6204 \\
\hline Brand familiarity $^{2}$ & 5.1 & 1.9 & 4.9 & 1.8 & 0.3289 \\
\hline
\end{tabular}

1: Two sample t-test for variables age to arousal; chi-square test for gender; result of ANOVA with repeated measures ( 31 sponsors) for the main effect of environment for congruence and brand familiarity.

2: Mean and standard deviation computed across all 31 sponsors i.e. $n=44 \times 31=1364$ observations in each environment. 


\section{Table II.}

Parameter estimates and standard errors from the marginal logistic regression model for recall and recognition using generalized estimating equations

\begin{tabular}{|c|c|c|c|c|c|c|}
\hline \multirow[b]{2}{*}{ Variables } & \multicolumn{3}{|c|}{ Recall } & \multicolumn{3}{|c|}{ Recognition } \\
\hline & $\begin{array}{c}\text { Parameter } \\
\text { estimate }\end{array}$ & $\begin{array}{l}\text { Std } \\
\text { error }\end{array}$ & $p$-value & $\begin{array}{c}\text { Parameter } \\
\text { estimate }\end{array}$ & Std error & $p$-value \\
\hline Intercept & -4.1088 & 0.4932 & $<0.0001$ & -2.5607 & 0.5193 & $<0.0001$ \\
\hline Age & 0.0105 & 0.0059 & 0.0765 & 0.0066 & 0.0071 & 0.3507 \\
\hline Brand familiarity & 0.1737 & 0.0317 & $<0.0001$ & 0.1415 & 0.0255 & $<0.0001$ \\
\hline Sponsor exposure frequency & 0.6571 & 0.0879 & $<.00001$ & 0.5085 & 0.0513 & $<0.0001$ \\
\hline Involvement with ice hockey & -0.1664 & 0.0713 & 0.0197 & -0.1655 & 0.0833 & 0.0471 \\
\hline Attendance games on-site & 0.1386 & 0.0495 & 0.0051 & 0.1829 & 0.0523 & 0.0005 \\
\hline Viewing games on television & 0.0093 & 0.0070 & 0.1804 & 0.0079 & 0.0084 & 0.3423 \\
\hline Environment & -0.0478 & 0.1749 & 0.7849 & -0.0454 & 0.2113 & 0.8299 \\
\hline Arousal $^{1}$ & -0.1784 & 0.1050 & 0.0893 & -0.3151 & 0.1308 & 0.0160 \\
\hline Congruence $^{1}$ & 0.0838 & 0.0481 & 0.0815 & 0.1278 & 0.0398 & 0.0013 \\
\hline Environment $*$ Arousal & 0.1788 & 0.1538 & 0.2451 & 0.3686 & 0.1702 & 0.0304 \\
\hline Environment $*$ Congruence & -0.0001 & 0.0622 & 0.9982 & -0.0501 & 0.0536 & 0.3502 \\
\hline Arousal $*$ Congruence & -0.1210 & 0.0578 & 0.0362 & -0.0826 & 0.0394 & 0.0364 \\
\hline Environment $*$ Arousal $*$ Congruence & 0.1525 & 0.0730 & 0.0367 & 0.1014 & 0.0525 & 0.0533 \\
\hline
\end{tabular}

1: Arousal and congruence were mean-centered in the statistical regression analyses 
Table III.

Estimated odds ratios (OR) and 95\% confidence intervals (C.I.) based on the marginal logistic regression model, for recall and recognition of sponsors between the on-site and television environments, at different levels of arousal and congruence.

\begin{tabular}{|c|c|c|c|c|c|c|c|}
\hline \multirow{3}{*}{$\begin{array}{c}\begin{array}{c}\text { Level of } \\
\text { arousal } \\
\text { (centered) }\end{array} \\
3(-2)\end{array}$} & \multirow{2}{*}{$\begin{array}{l}\text { Level of } \\
\text { congruence } \\
\text { (centered) }\end{array}$} & \multicolumn{3}{|c|}{ Recall } & \multicolumn{3}{|c|}{ Recognition } \\
\hline & & \multirow{2}{*}{$\begin{array}{c}\text { OR } \\
1.6655\end{array}$} & \multicolumn{2}{|c|}{ 95\% C.I. } & \multirow{2}{*}{$\frac{\text { OR }}{0.9764}$} & \multicolumn{2}{|c|}{ 95\% C.I. } \\
\hline & $1(-3)$ & & 0.5309 & 5.2245 & & 0.3555 & 2.6816 \\
\hline & $2(-2)$ & 1.2275 & 0.4956 & 3.0403 & 0.7582 & 0.3195 & 1.7994 \\
\hline & $3(-1)$ & 0.9047 & 0.4381 & 1.8680 & 0.5888 & 0.2736 & 1.2673 \\
\hline & $4(0)$ & 0.6667 & 0.3497 & 1.2711 & $0.4572^{*}$ & 0.2188 & 0.9554 \\
\hline & $5(1)$ & $0.4914^{*}$ & 0.2433 & 0.9926 & $0.3551^{*}$ & 0.1623 & 0.7768 \\
\hline & $6(2)$ & $0.3622 *$ & 0.1515 & 0.8659 & $0.2757^{*}$ & 0.1129 & 0.6734 \\
\hline & $7(3)$ & $0.2669 *$ & 0.0887 & 0.8029 & $0.2141^{*}$ & 0.0752 & 0.6101 \\
\hline \multirow{7}{*}{$4(-1)$} & $1(-3)$ & 1.2603 & 0.6168 & 2.5754 & 1.0414 & 0.5409 & 2.0050 \\
\hline & $2(-2)$ & 1.0819 & 0.6084 & 1.9241 & 0.8950 & 0.5079 & 1.5770 \\
\hline & $3(-1)$ & 0.9288 & 0.5811 & 1.4844 & 0.7691 & 0.4620 & 1.2805 \\
\hline & $4(0)$ & 0.7973 & 0.5241 & 1.2128 & 0.6610 & 0.4026 & 1.0854 \\
\hline & $5(1)$ & 0.6844 & 0.4377 & 1.0701 & $0.5681^{*}$ & 0.3349 & 0.9637 \\
\hline & $6(2)$ & 0.5875 & 0.3425 & 1.0077 & $0.4882^{*}$ & 0.2680 & 0.8894 \\
\hline & $7(3)$ & $0.5043^{*}$ & 0.2578 & 0.9865 & $0.4196^{*}$ & 0.2087 & 0.8434 \\
\hline \multirow{7}{*}{$5(0)$} & $1(-3)$ & 0.9538 & 0.5564 & 1.6349 & 1.1106 & 0.6349 & 1.9428 \\
\hline & $2(-2)$ & 0.9536 & 0.6076 & 1.4966 & 1.0564 & 0.6449 & 1.7304 \\
\hline & $3(-1)$ & 0.9535 & 0.6511 & 1.3963 & 1.0047 & 0.6449 & 1.5652 \\
\hline & $4(0)$ & 0.9534 & 0.6767 & 1.3432 & 0.9556 & 0.6315 & 1.4460 \\
\hline & $5(1)$ & 0.9532 & 0.6749 & 1.3464 & 0.9089 & 0.6027 & 1.3706 \\
\hline & $6(2)$ & 0.9531 & 0.6465 & 1.4051 & 0.8645 & 0.5603 & 1.3337 \\
\hline & $7(3)$ & 0.9530 & 0.6015 & 1.5098 & 0.8222 & 0.5093 & 1.3274 \\
\hline \multirow{7}{*}{$6(1)$} & $1(-3)$ & 0.7218 & 0.3230 & 1.6127 & 1.1845 & 05220 & 26878 \\
\hline & $2(-2)$ & 0.8406 & 0.4338 & 1.6288 & 1.2468 & 0.6084 & 2.5552 \\
\hline & $3(-1)$ & 0.9789 & 0.5648 & 1.6967 & 1.3124 & 0.6986 & 2.4657 \\
\hline & $4(0)$ & 1.1400 & 0.6978 & 1.8624 & 1.3815 & 0.7847 & 2.4319 \\
\hline & $5(1)$ & 1.3277 & 0.8029 & 2.1954 & 1.4541 & 0.8556 & 2.4715 \\
\hline & $6(2)$ & 1.5462 & 0.8642 & 2.7666 & 1.5306 & 0.8999 & 2.6035 \\
\hline & $7(3)$ & 1.8007 & 0.8893 & 3.6460 & 1.6111 & 0.9132 & 2.8424 \\
\hline \multirow[t]{7}{*}{$7(2)$} & $1(-3)$ & 0.5462 & 0.1555 & 1.9185 & 1.2634 & 0.3704 & 4.3084 \\
\hline & $2(-2)$ & 0.7409 & 0.2679 & 2.0491 & 1.4717 & 0.5072 & 4.2702 \\
\hline & $3(-1)$ & 1.0050 & 0.4377 & 2.3075 & 1.7144 & 0.6770 & 4.3415 \\
\hline & $4(0)$ & 1.3632 & 0.6511 & 2.8544 & 1.9971 & 0.8699 & 4.5851 \\
\hline & $5(1)$ & 1.8492 & 0.8519 & 4.0141 & $2.3265^{*}$ & 1.0606 & 5.1031 \\
\hline & $6(2)$ & 2.5084 & 0.9952 & 6.3224 & $2.7101 *$ & 1.2161 & 6.0395 \\
\hline & $7(3)$ & $3.4025^{*}$ & 1.0843 & 10.6775 & $3.1570^{*}$ & 1.3157 & 7.5753 \\
\hline
\end{tabular}


Figure 1a. Estimated probability of sponsor recall among participants watching the game on television

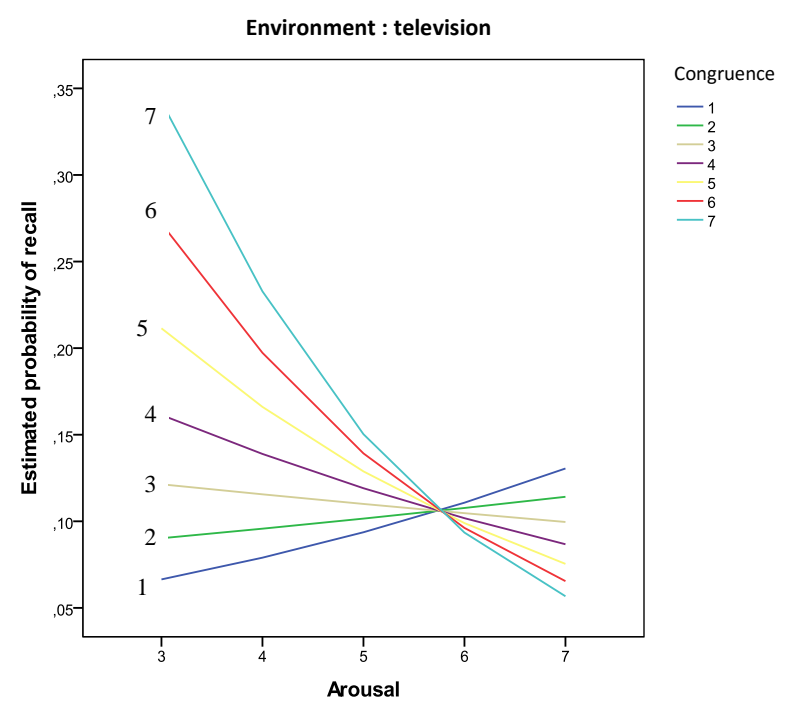

Figure 2a. Estimated probability of sponsor recognition among participants watching the game on television

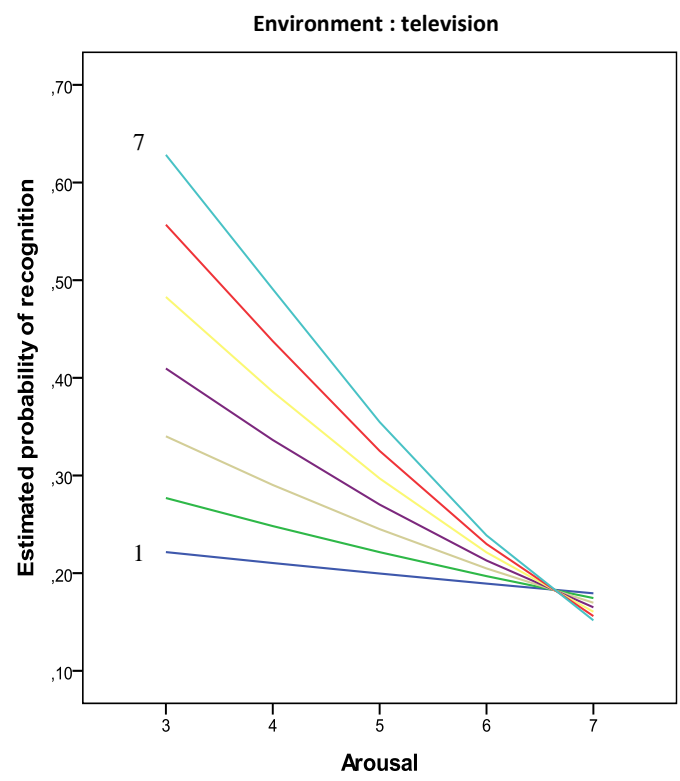

Figure 1b. Estimated probability of sponsor recall among participants watching the game onsite

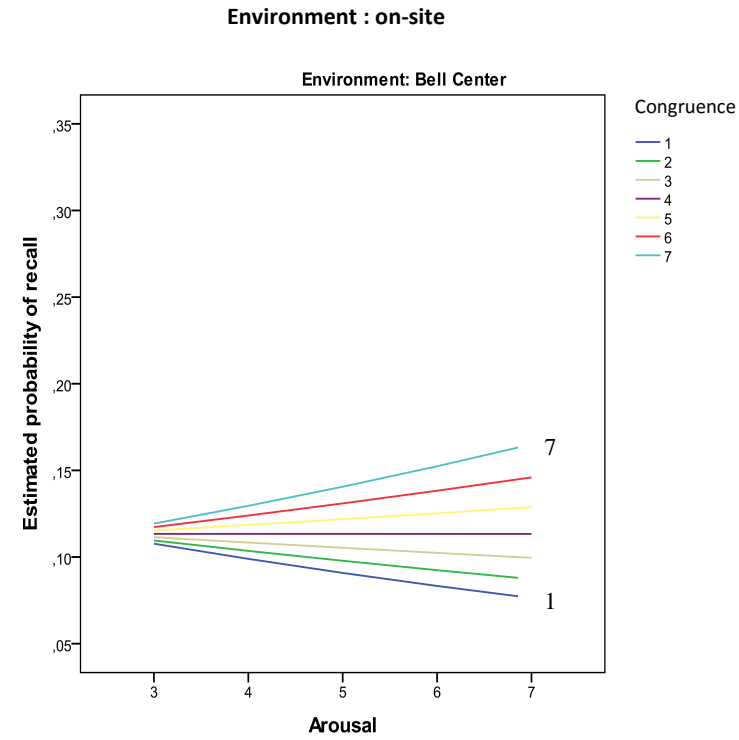

Figure 2b. Estimated probability of sponsor recognition among participants watching the game on-site

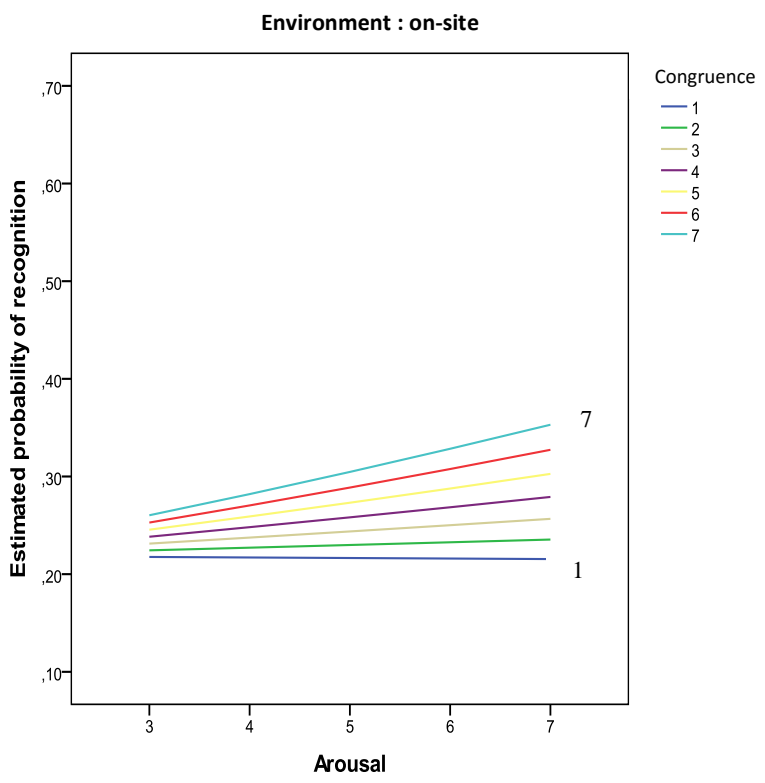

